7. Reprod. Fert. (1973) 34, 175-177

\title{
MODIFICATION OF THE RAT UTERINE WEIGHT RESPONSE TO HUMAN CHORIONIC GONADOTROPHIN BY OESTROGEN
}

\author{
L. J. HIPKIN \\ Endocrine Unit, Liverpool Clinic, Myrtle Street, Liverpool L7 7DE
}

(Received 30th January 1973)

Dehydroepiandrosterone (DHA) and ACTH stimulated uterine growth and augmented the uterine weight response to HCG in intact rats (Hipkin, 1971). These responses were not observed in hypophysectomized animals and it was concluded that DHA increased pituitary gonadotrophin secretion, possibly following its conversion to oestrogen. This paper records the effect of oestradiol on HCG activity in the uterine weight assay, the oestrogen being given in a dose which itself did not stimulate uterine growth.

Sixty female Wistar rats from an inbred colony (originating from Tuck's strain), 20 to 22 days old and weighing 30 to $45 \mathrm{~g}$, were allocated to five groups. Four of the groups were given HCG in total doses ranging from 0.2 to 1.6 i.u. The injections were given subcutaneously in $0.5 \mathrm{ml}$ water daily for 3 days. The remaining group did not receive HCG. The groups were further subdivided, the rats in one half being treated with a total of $0.02 \mu \mathrm{g}$ oestradiol in olive oil while the control rats were injected with the vehicle alone. These injections were also administered subcutaneously $(0.1 \mathrm{ml}$ daily) at the same time as HCG but at a different site. On the 4th day, the animals were killed and weighed, and the ovarian and uterine weights were obtained. The potency ratio (with fiducial limits), calculated by the method of Gaddum (1953), was used to determine the effect of oestrogen on HCG activity in the uterine weight assay. Mean ovarian weights and some individual uterine weights were compared using Student's $t$ test.

Oestradiol, in a dose of $0.02 \mu \mathrm{g}$, did not significantly affect uterine weight, the mean in the group being $22.4 \pm 1.3 \mathrm{mg}$ compared with $20.6 \pm 0.7 \mathrm{mg}$ in the control series. The mean uterine weights in the control groups treated with 0.2 i.u. and 0.4 i.u. HCG were not significantly different from the basal value (Text-fig. 1). Oestradiol did increase the sensitivity of the uterine weight to HCG, however, and significant responses $(P<0.01$ and $P<0.01)$ to the two lowest doses of HCG were produced. Oestradiol potentiated the response to 0.8 i.u. HCG and from the data, it was calculated that HCG was 1.35 (1.08 to 1.62) times as active in the oestrogen-treated groups. There were no differences in mean ovarian weights when the oestrogen-treated and control groups were compared.

The dose of oestradiol chosen for the present investigation was just insufficient to stimulate uterine growth (L. J. Hipkin, unpublished data). Three possible 
hypotheses can be advanced to explain the potentiation of HCG activity produced by this dose of oestrogen. Firstly, it is possible that the increase in sensitivity to the small doses of HCG is due to the combined action of exogenous and endogenous oestrogen, neither alone being sufficient to stimulate uterine growth. This would not account, however, for the potentiation of the uterine weight response to $0 \cdot 8$ i.u. HCG since the injected oestradiol would add relatively little to the increased pool of oestrogens of ovarian origin. Secondly, pharmacological doses of oestrogen directly stimulate proliferation of the granulosa cells, with a consequent increase in ovarian weight and augmentation of the ovarian weight response to FSH and HCG (Smith \& Bradbury, 1967).

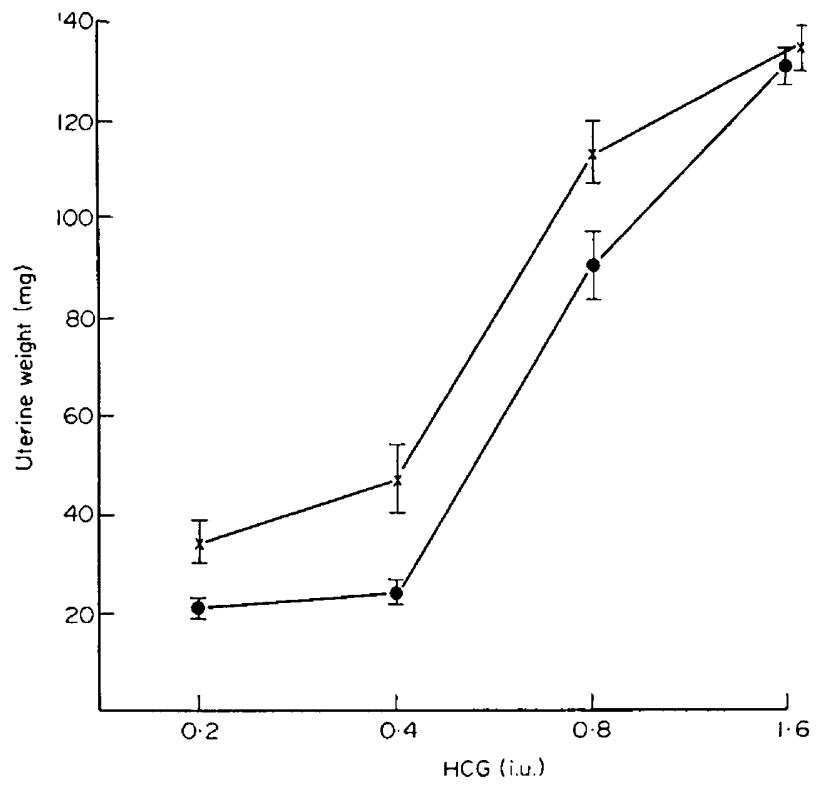

TEXr-FIG. 1. Uterine weight responses to HCG in the rats treated with olive oil $(0)$ and oestrogen $(x)$. Vertical lines indicate the S.E. of the mean.

Oestrogen also increases the ovarian uptake of FSH (Goldenberg, Vaitukaitis \& Ross, 1972). Presumably, increased oestrogen secretion accompanies these changes. In the present investigation, physiological doses of oestrogen were used and ovarian weight responses to HCG were unaffected. Thirdly, Smith \& Bradbury (1967) noted that oestrogen failed to enhance ovarian growth in hypophysectomized rats given HCG and concluded that some of the responses they had observed were effected by endogenous gonadotrophin from the pituitary gland. Direct evidence for the release of pituitary gonadotrophin following treatment with low doses of oestrogen was reported by Ramirez \& Sawyer (1965). This third possibility is the most likely explanation for the augmentation of HCG activity found in the present investigation.

The findings in this report suggest the hypothesis that the potentiation of HCG activity by DHA (Hipkin, 1971) is an oestrogenic effect. A further point of interest is the possible value of using oestrogen in the bioassay of HCG. 
Injections of inert toxic urinary extracts also potentiated HCG activity by release of endogenous gonadotrophin, and the use of hypophysectomized animals in such circumstances was recommended (Hipkin, 1970). There was a considerable loss of sensitivity, however, when uterine weight responses to HCG were carried out in hypophysectomized animals (Hipkin, 1970). Differences in endogenous gonadotrophin secretion between test and reference groups of rats may be overcome by treatment of all animals with oestrogen.

\section{REFERENCES}

Gaddum, J. H. (1953) Simplified mathematics for bioassays. F. Pharm. Pharmac. 5, 345.

Goldenberg, R. L., VAITUKAItis, J. L. \& Ross, G. T. (1972) Estrogen and follicle stimulating hormone interactions on follicle growth in rats. Endocrinology, 90, 1492.

HIPKIN, L. J. (1970) The effect of the urinary gonadotrophin inhibitor on the rat uterine weight response to human chorionic gonadotrophin. Acta endocr., Copenh. 64, 421.

Hipkin, L. J. (1971) The effect of corticotrophin on the rat uterine weight response to human chorionic gonadotrophin. Acta endocr., Copenh. 67, 463.

Ramirez, V. D. \& SawYer, C. H. (1965) Advancement of puberty in the female rat by estrogen. Endocrinology, 76, 1158.

SMIth, B. D. \& BRADbURY, J. T. (1967) Ovarian response to gonadotrophins after pretreatment with diethylstilbestrol. Am. F. Physiol. 204, 1023. 